\title{
$<$ inter

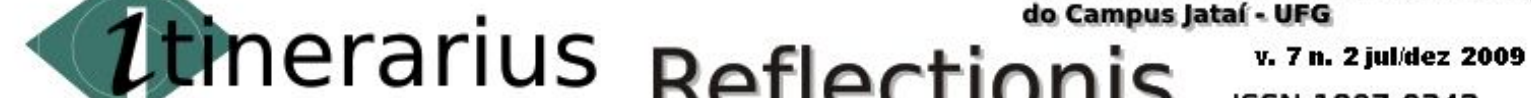

\section{IDADE MÉDIA POR UMA FÉ RACIOCINADA: UMA LEITURA EM SANTO AGOSTINHO E SÃO TOMÁS DE AQUINO}

\author{
Aline de Fátima Sales Silva ${ }^{1}$
}

\begin{abstract}
This article discusses the relationship between faith and reason in the Middle Ages. Unjustly accused of obscurantism between the intellectuals, the Middle Ages was a time of profound cultural effervescence and philosophical reflections. The theory of the Catholic Church, especially St. Augustine and St. Thomas Aquinas, made an important research work in order to understand the issues of faith und the issues of faith under the scrutiny of rationality. Based on Plato and Aristotle, respectively, they renewed the concepts and ideas of the Platonic and Aristotelian philosophy for understanding of divine truths. This work that marked significantly the history of Western Christianity and medieval philosophy.
\end{abstract}

Key word: Philosophy, Christianity; between and reason.

Resumo: Este artigo discute a relação entre fé e razão na Idade Média. Injustamente acusada de obscurantismo no campo da intelectualidade, a Idade Média foi um tempo efervescência cultural e de profundas reflexões filosóficas. Os teóricos da igreja Católica, especialmente Santo Agostinho e São Tomás de Aquino, realizaram um grandioso trabalho de pesquisa no intuito de compreender as questões da fé sob o crivo da racionalidade. Fundamentados em Platão e Aristóteles respectivamente, ressignificaram e reconduziram os conceitos e idéias da filosofia platônica e aristotélica para entendimento das verdades divinas. Trabalho que marcou significativamente a história do cristianismo ocidental e a filosofia medieval.

Palavras- chave: filosofia, cristianismo, fé, razão.

Nas ações humanas, tudo o que vai contra a razão é vicioso.

Tomás de Aquino

O tempo que compreende os mil anos que denominamos Idade Média nos foi apresentado pelos livros de história no ensino fundamental e médio, como um tempo de obscuridade e inércia

\footnotetext{
${ }^{1}$ Mestre em Educação Brasileira pelo Programa de Pós-Graduação da Faculdade de Educação UFG, membro do Grupo de Estudos de Filosofia e Educação da FE/UFG.
} 
intelectual. Um período de sombras em que o domínio da igreja católica ostraliza as mentalidades e impede a formação do pensamento em todos os âmbitos.

O livro que baseou o filme "O Nome da Rosa", de Humberto Eco, mostra essa imagem de forma visível. Todas as atrocidades contra os intelectuais que se opunham a igreja são mostradas de forma exagerada e pejorativa. A própria obscuridade aparece na gravação, sempre sombria e escura das cenas justapostas, demonstrando na representação artística essa visão da Idade Média como um tempo de trevas, escuridão e ostracismo intelectual.

Essa é a imagem que marcou a nossa formação, no período de escolarização.

Hilário Franco Júnior, brilhante historiador da Idade Média, demonstra que o próprio termo denominado a esse período carrega consigo essa idéia medíocre, período sem identidade própria, algo mediano entre os séculos que compreendem a Antiguidade Clássica e a Modernidade proclamada pelos renascentistas no século XVI.

A Idade Média é para os renascentistas, a decadência das letras e das artes. Para os iluministas, o momento em que o mundo parou, oprimiu a razão e retrocedeu a toda construção intelectual que antiguidade clássica elaborou. Hilário Franco descreve bem o sentimento dos renascentistas em relação a esse período quando diz que para eles:

(...) a Idade Média teria sido, uma interrupção no progresso humano, inaugurado pelos gregos e romanos e retomado pelos homens do século XVI. Ou seja, também para o século XVII, os tempos "medievais" teriam sido de barbárie, ignorância e superstição (FRANCO JÚNIOR, 2004, p. 12).

Os renascentistas e iluministas, inebriados pelo ideal de laicização do saber, na crença inexorável na racionalidade científica como verdade desvelada, e no progresso da ciência, desmantelam o conhecimento teológico, que é a verdade revelada. Mostram-se, com toda a sua pseudo superioridade, como referência de explicação do mundo em permanente descoberta.

Toda essa herança preconceituosa nos foi passada naturalmente no discurso acadêmico, muitas vezes desprovido de reflexão, de avaliação, de critério com o saber e por extrema falta de cuidado com o estudo e com o rigor na pesquisa.

Se for verdade que a Idade Média representou certo momento de trevas, dada às invasões, epidemias como a "peste negra", guerras intermináveis, conquistas de terras, lutas e domínio do Império Romano, é verdade também que houve, indiscutivelmente nesse período, um florescimento cultural muito grande, importantíssimos à construção da cultura ocidental.

Portanto, se desejarmos conhecer criteriosamente o que representou a Idade Média em termos de produção intelectual e herança acadêmica é importante abandonarmos essa imagem distorcida, enviesada, falseada que nos foi passada nos primeiros anos de nossa formação e embarcar em um universo denso, porém, instigante do estudo e da pesquisa, da leitura rigorosa dos grandes intelectuais

desse tempo.

Para o propósito deste trabalho escolhi especificamente, Santo Agostinho e São Tomás de Aquino, pela construção teórica de suas obras, sem desprezar outros pensadores desse período, porque o trabalho desses dois grandes mestres da Idade Média representa em seu conjunto o ideário teológico mais profícuo em quantidade e qualidade desse momento da história da humanidade. 
Para entender como as humanidades se tornaram o fundamento da teologia cristã, é preciso recuar a momentos da história universal a fim de compreender o processo de construção do pensamento ocidental.

Quando em 392 o Império Romano adota o cristianismo como religião oficial ao mesmo tempo em que o imperador Constantino tentou sustentar o domínio romano, buscando o apoio e adesão dos cristãos, uma nova era é inaugurada na consolidação da religião do Cristo e no nascimento da Igreja Católica Apostólica Romana, como sucessora e herdeira do poderio ideológico e econômico do Império. Sobre essa relação entre Império e Igreja, Hilário Franco Júnior (2004, p. 67) diz que:

Nascida dos quadros do Império Romano, a igreja ia aos poucos preenchendo os vazios deixados por ele, até em fins do século IV, identificar-se com o Estado, quando o cristianismo foi reconhecido como religião oficial. A Igreja passava a ser herdeira natural do Império Romano.

Essa oficialização, é claro, foi uma das tentativas do imperador de estabelecer novas estruturas sociais no intuito de sustentar império em decadência, unificando romanos e germanos, forjando a unidade espiritual essencial para a consolidação da civilização medieval.

De religião proibida, o cristianismo passou a ser a religião oficial do império. As primeiras testemunhas do Cristianismo, homens simples, camponeses, pobres, estropiados de toda sorte, foram sucedidos pelos doutos da época. Uma mudança radical foi empreendida nos dogmas dessa fé. Das reuniões clandestinas nas catatumbas, o culto cristão ascendeu para grandes e ricos templos nas praças públicas. De religião dos simples passou-se a religião dos conhecedores das leis. A fé cristã se tornou instrumento de prestígio e dominação, apropriada pelos intelectuais da época.

Dominar pela fé era tarefa fácil para uma realeza reconhecida como a própria manifestação do poder divino, de modo que nesse período o político e o religioso estavam imbricados e se fundiam um no outro.

Durante os quatro períodos da Idade Média delimitados por Hilário Junior ${ }^{2}$, observamos essa relação intrínseca entre o político e o religioso, de forma que a religião vai alastrando sua área de domínio, principalmente a partir das trocas comerciais com Carlos Magno ${ }^{3}$, durante o Império Carolíngio.

De certo modo nessa relação, o religioso começa a ceder espaço para a construção do político como apêndice da igreja, enquanto, a igreja expande seu domínio geográfico anexando cada vez mais terras sob seu comando, essas terras, além do seu valor comercial acarretaram poder político e ideológico à igreja.

\footnotetext{
${ }^{2}$ Hilário Franco Júnior considerando a história como processo apresenta em sua obra (p. 15-16), uma periodicização da Idade Média que se estende dos séculos IV ao XVI subdivididos em: Primeira Idade Média, que vai se estende do início do séc. IV à meados do séc. VIII; Alta Idade Média que vai de meados do séc. VIII à fins do séc. X; Idade Média Central do séc. XI ao séc. XIII e por fim, Baixa Idade Média que se estende do séc. XIV à meados do séc. XVI. (2001, p. 15-17).

${ }^{3}$ Carlos Magno filho mais velho de Pepino o Breve, foi coroado Imperador pelo Papa Leão III em 800, aliou-se a Igreja pelo reconhecimento e legitimidade de seu poder como imperador e em troca doava à Igreja terras que compreendiam vasta extensão do território Italiano. (FRANCO, Júnior, 2001, p. 54).
} 
As conquistas de territórios nesses tempos tornaram a igreja a maior proprietária de terras em todo o período que compreende a Idade Média. No século IX seu latifúndio representava 1/3 das terras cultiváveis de todo o Ocidente Cristão, tornando-a hegemônica não apenas pela ideologia, mas principalmente pela economia.

O domínio cultural também foi hegemônico. A igreja tomou para si a cultura letrada. A leitura e a escrita eram pouco difundidas entre o povo e os maiores conhecedores das letras eram os clérigos. Assim, o poder ideológico era exercido com toda sua força na formação da opinião das massas.

A Bíblia era lida e interpretada a partir dos conceitos e ideais da Igreja, criando um modelo de homem cristão que se manifesta no plano simbólico, representando seus anseios. Isso que faz dela um verdadeiro Estado, copiando inclusive a organização administrativa do regime civil do Baixo Império Romano.

A estrutura mental medieval colocava Deus como centro de todas as coisas e a Igreja pretendia ser ela própria o centro do mundo, constituindo a tríade - um só Deus, uma só fé, uma só Igreja - Autoridade máxima supostamente universal, pressupunha a tarefa de encontrar em toda parte a ordem de Deus.

Esse encontro com Deus assume na religião Católica Apostólica Romana um caráter racionalista. Torna-se necessário conhecer para crer e o estudo se torna fonte informação para o entendimento de Deus. A Igreja Católica produziu uma filosofia com a preocupação de demonstrar e sistematizar a fé. Realizou esse esforço para tornar os fundamentos cristãos aceitos não apenas por sua revelação, mas por sua racionalidade.

Consolidada como religião culta por seu principal expoente e difusor Paulo da cidade de Tarso, o campo da fé começa a exigir reflexão, razão, estudo e disciplina.

Paulo, judeu, cidadão romano, educou-se no ambiente imerso na vasta cultura helênica. Homem culto, inteligente, conhecedor das leis romanas e da ciência de seu tempo, ao se converter para o cristianismo às portas da cidade de Damasco após o encontro com Cristo, toma para si a tarefa de edificar e divulgar a religião Cristã.

Utilizando a arte da oratória, ele encontra argumentos que convencem judeus e pagãos nas cidades em que passa. Após sua prisão, escreve cartas aos fiéis de sete cidades e aos companheiros de fé. Em seus escritos Paulo discute, argumenta, provoca o raciocínio e demonstra com rigor os fundamentos de sua fé.

Considerá-lo primeiro teólogo do cristianismo não seria de tudo absurdo, já que em suas cartas podemos observar uma preocupação em sistematizar os conhecimentos de uma doutrina cristã. Conhecimentos de ordem divina, que segundo ele, pertencem à outra dimensão, a dimensão do espírito (Cf. I EPÍSTOLA AOS CORÍNTIOS 2, 4 à 5).

Em várias passagens da obra de Paulo de Tarso encontramos esse paradoxo entre a sabedoria deste mundo e a sabedoria do espírito (Cf. I COR. 1,17 à 31; 2, 6 à 16; II COR. 1,12 à 13; EFE. 3,19; TIA. 3, 13 à 16).

A sabedoria do espírito é divina, no entanto, não é de modo algum irracional, cega, mas, examinada como afirma Paulo na I epistola a João: "não deis fé a qualquer espírito, mas, examinai se os espíritos são de Deus." (I JOÃO 4,1.) Nesta passagem Paulo reconhece o valor do exame e do trabalho intelectual na busca da verdade o que comprova o caráter racional de sua doutrina. Ele fazia distinções, examinava, refletia, comparava os ensinamentos de Cristo com os ensinamentos judaicos, discordava e argumentava, assumia uma postura demonstrativa acima de tudo. Era filósofo, teólogo por natureza. 
Paulo demonstrava do ponto de vista da fé raciocinada, pensada não pelo viés da sabedoria do mundo, mas do espírito, edificando divulgando a doutrina do Cristo que se consolida em todo o Ocidente.

Com o triunfo do cristianismo em 313 pela concessão da liberdade de culto aos cristãos e posteriormente em 397 com oficialização da religião, o cristianismo se estabelece organizado sob a autoridade dos padres, bispos e papas, sob a égide da recente instituição criada para esse fim: a Igreja.

Diante dessa nova realidade, a Igreja toma para si a tarefa de interpretar para ressignificar a mensagem de Jesus. Nesse período as disputas pela melhor interpretação dos conceitos cristãos foram acirradas, confronto que no plano político se resolveu no Concílio de Nicéia em 325, convocado pelo Imperador Constantino, com o objetivo de estabelecer a ortodoxia, a opinião correta da doutrina cristã.

Apesar da autoridade do poder do Concílio para estabelecer a ortodoxia, era importante que ela fosse convincente, que apresentasse coerência, lógica, resultado de raciocínios bem elaborados, demonstrações bem construídas do ponto de vista da argumentação para que pudesse convencer não só os pagãos e os céticos como também os próprios cristãos.

A filosofia patrística representa esse trabalho de munir a fé de argumentos lógicos em busca de uma explicação racional para a crença. Essa tarefa será empreendida com empenho pelos padres da Igreja, principalmente por São Tomás de Aquino e Santo Agostinho.

Santo Agostinho nasceu em 354 na Argélia, e, por esforço de sua mãe, pode completar seus estudos e tornar-se bispo da Igreja. De vida puramente mundana até os 32 anos de idade, converteu-se a religião do Cristo, após anos de reflexão e solidão. Na religião encontrou sua verdadeira vocação, o sentido maior de sua existência.

Estudioso da filosofia grega e preocupado com as questões essenciais da existência humana, Agostinho se propôs a entender a finalidade maior da vida, que seria para ele a felicidade do homem.

A felicidade se realiza plenamente na ascensão do espírito à vida contemplativa, ao encontro de Deus. Contemplar no sentido platônico, elevar-se ao plano das idéias, do imutável, do imaterial, à aquilo que diz respeito ao mundo do espírito.

Para Santo Agostinho, essa elevação só é possível por um exercício de busca interior um trabalho intelectual profundo e solitário no sentido de encontrar o Mestre interior, o Cristo que habita em cada um dos homens e que os faz compreender a essência de todas as coisas. Portanto, a compreensão da realidade espiritual, exige o uso sensato e reflexivo da inteligência e da razão.

Para atingir o nível de existência sublime, Agostinho dizia que era necessário crer, entretanto, para crer é necessário entender de modo que a fé pressupõe a razão e se mantém nela. Para ele, fé e razão convivem de forma harmônica numa estreita colaboração. É o que observa Zilles (1996, p.40), quando diz que para $\mathrm{St}^{\circ}$ Agostinho:

a inteligência prepara a fé; depois a fé dirige e ilumina a inteligência. Finalmente a fé, iluminada pela inteligência conduz ao amor. Desta forma vai do entendimento para a fé e da fé para o entendimento e de ambos para o amor.

Nessa perspectiva, a relação entre fé e razão é intrínseca e endógena. A existência de uma se realiza na existência da outra, numa relação recíproca, de modo que, pela fé atingimos a 
razão e pela razão iluminamos a fé. Assim, é necessário crer como primeiro passo para o entendimento, diz ele no Sermão 43, s/d :

Todos los hombres quieren entender; nadie hay que no lo quiera, mas no todos quieren creer. Se me dice:<Entienda yo y creeré>. Yo lê respondo: <Cree y entenderás>.

Na carta 120, Agostinho é ainda mais incisivo ao demonstrar como a fé e a razão se relacionam e são virtudes propriamente humanas, reguladas por Deus o que afasta a idéia do pecado no questionamento e na busca:

Que Deus nos defenda de pensar que ele odeie em nós aquilo que nos criou superiores aos outros animais! Não apraza a Deus que a fé nos impeça de receber ou de pedir a razão do que cremos! Nem sequer poderíamos crê se não possuíssemos almas racionais (AGOSTINHO, 1957, P. 148).

Fundamentado nos princípios platônicos, Agostinho realiza a transposição desses conceitos para explicar e justificar a sua fé. O conceito de Idéia, traduz

e explica a essência de Deus, o mundo das Idéias platônico representa o mundo espiritual, a verdadeira pátria do espírito, lugar onde vislumbramos os arquétipos eternos e imutáveis de toda a realidade criada por Deus.

Pela razão depositada por Deus na alma humana é possível conhecer a verdade, e conhecer a verdade é conhecer a Idéia, forma pura, universal e eterna do ser em essência que se revela no âmago de cada um, através do mestre interior, não por rememoração como vemos em Platão, mas pela luz divina que habita em cada criatura, e explica:

Em tudo o que compreendemos, o que importa não é uma palavra que soa exteriormente, respondendo a nossa consulta, senão a verdade que governa $o$ próprio espírito no interior, servindo talvez os vocábulos apenas para nos advertir que o façamos. Ora, quem assim consultamos é o próprio Mestre, aquele de quem é dito que habita no homem interior, o Cristo, isto é, a força imutável de Deus e sabedoria eterna.(SANTO AGOSTINHO, De Magistro 1957, p. 90).

O conhecimento da verdade como sabedoria eterna está ligado ao conceito de Idéia, construído por Platão, que apropriado por Agostinho, foi fundamental para o aprofundamento da doutrina cristã nos rigores da racionalidade. É a busca da essência, da substância, daquilo que é, o que pode ser verdadeiramente racional e cognoscível, e isso torna a religião cristã força e expressão da intelectualidade a serviço da fé. Diz ele:

Ninguém está de forma alguma justificado para dizer que conhece uma coisa enquanto ignorar-lhe a substância. É por esta razão que quando o pensamento se conhece, conhece também a própria substância, e uma vez que esteja certo de si estará também certo da própria existência. (SANTO AGOSTINHO, De Trindade X-10-15-16, 1957, p. 99)

A perspectiva do conhecimento cristão exige reflexão acurada, superação do que os sentidos nos mostram, transcendência da matéria para atingir a verdade espiritual com o fim de 
conhecer a essência, o que acontece tanto por meio da razão como pela paixão como afirmou Santo Agostinho em A cidade de Deus XI- 26:

Pois nós somos e sabemos o que somos, e amamos o nosso ser e o nosso conhecimento. E estamos seguros da verdade dessas três coisas. Pois não é como os objetos de nossos sentidos que podem nos enganar por uma noção falsa. Estou absolutamente certo por mim mesmo que eu sou, que eu conheço e que eu amo o meu ser (SANTO AGOSTINHO, 1957, p. 99).

Foi pelo trabalho minucioso do estudo com rigor e disciplina, que Agostinho realizou a tarefa de demonstrar pela autoridade do pensamento, submetida à razão, o sentido do texto bíblico, na perspectiva do "logos", o verbo de Cristo para os homens de boa vontade.

Em uma trajetória parecida, São Tomás de Aquino, nascido no Castelo de Rocasseca, perto de Aquino, tornou-se outro importante teórico da Igreja Católica. Estudou nos mosteiros da ordem Beneditina e lá iniciou seu apostolado eclesiástico.

Intensamente estudioso e disciplinado, o que era natural para um discípulo beneditino, Tomás de Aquino se inquietou profundamente com o debate intelectual de seu tempo. As discussões que emergiam nesse momento, contrapunham o conhecimento pela fé e pela razão, liberdade racional e desconfiança dogmática, teologia e filosofia, crença na revelação bíblica e investigações dos filósofos gregos. ${ }^{15}$

De espírito profundamente investigativo e inquiridor, debruçou-se no estudo das obras de Aristóteles, apesar de suas limitações quanto à língua grega, que ele não conhecia. Pôde aprofundar seu conhecimento nos conceitos fundamentais da filosofia aristotélica com a ajuda de intérpretes e tradutores como Guilherme de Moerbeke.

A principal fonte de pesquisa de São Tomás são as obras de Aristóteles e o conhecimento formulado pela tradição neoplatônica cristã, sistematizada especialmente por Santo Agostinho. Diante desse conhecimento Tomás de Aquino reinterpreta a filosofia de Aristóteles pelo viés da doutrina cristã, no sentido de conciliar criticamente a fé e a razão, a fim de ascender ao conhecimento de Deus.

Para Tomás de Aquino, somente pela razão e pelo juízo reto é que se pode alcançar a fé como condição essencial ao encontro da verdade revelada. Pela razão, encontrou os pilares para fundamentar a fé católica e provar a existência de Deus. Diz ele:

para que a inteligência humana adira perfeitamente à verdade da fé, duas condições se exigem. Uma, compreender bem o objeto proposto; o que compete ao dom da inteligência, como acima foi dito. Outra, ter juízo certo e reto do objeto proposto, discernindo o que deve ou não deve crer (TOMÁS DE AQUINO, Suma Teológica.Questão 09: O dom da ciência. Art. I, 2003, p. 145).

Preocupado em conhecer a verdade em si e demonstrar como esta pode concordar com a fé, ele estabelece as bases para o entendimento da realidade espiritual e as provas da existência de Deus.

Compreendendo o conceito de causa primeira ou causa final em Aristóteles, ou seja, a causa que explica todas as causas estabelece a relação entre causa e efeito do movimento de todo o universo, o que explica a permanência e a mudança em todas as coisas, de modo que a existência de Deus é provada, segundo o filósofo, partindo do princípio de que: se todo efeito provém de uma causa e uma causa não pode causar a si mesmo, a causa primeira de todas as 
coisas é o supremo bem, que é Deus. Uma primeira causa não causada, causa sui, causa de si mesmo, que é ao mesmo tempo causa primária e causa final. Motor imóvel que governa o mundo, causa eficiente, ente ao máximo, verdade suprema.

Tomás de Aquino reconhece a razão como a luz natural que nos possibilita a compreensão plena de Deus, que nos conduz a verdade maior e a finalidade da existência humana.

Para ele, o fim do homem é o aperfeiçoamento de sua natureza, que se cumpre em Deus. As virtudes morais e sociais dos homens devem ser cultivadas para que ele possa alcançar o Bem maior que é a causa final de sua existência, como afirma: "Ora, o bem do homem consiste em viver conforme a razão, como diz Dionísio. Portanto, a virtude humana é a que inclina ao que está de acordo com a razão" (TOMAS DE AQUINO, St ${ }^{\circ}$. Suma Teológica. Questão 141: A temperança, art. I, 2003, p.188).

Tudo o que esta de acordo com a razão é equilibrado, é a justa medida, nisto consiste a felicidade do homem. A conquista das virtudes supõe a busca da excelência de vida, uma vida temperante liberta dos bens materiais dos quais somos apenas usuários e não proprietários, liberta de tudo o que acorrenta o homem da esfera do imediato, do superficial, do empírico, como nos diz Tomás de Aquino: "o homem deve sempre procurar se prover mais dos bens espirituais, e neste domínio é sempre possível a cada um abastecer cada vez mais a si próprio" (TOMAS DE AQUINO, Stº. Suma Teológica, A Liberalidade. Questão; 117, art. I, 2003, p. 656).

Abastecer cada vez mais o espírito das virtudes morais, engrandecer a alma e os horizontes, tornar-se magnânimos, romper com a mediocridade da materialidade e conquistar a dignidade de sermos humanos.

Conquistarmos uma vida virtuosa, vida de qualidade, sempre guiados e pela razão em todas as nossas atitudes, é que consiste a finalidade maior da existência humana.

A questão da razão como guia de orientação e entendimento da fé é marcante na obra de Tomás de Aquino. Sua leitura e reorientação dos conceitos Aristotélicos para a fé cristã foi extremamente valorosa sob pelo menos três aspectos: i. permitiu a divulgação dos conceitos filosóficos de Aristóteles que foram durante alguns séculos censurados pela Igreja Católica; ii. cumpriu com seu objetivo de esclarecer a fé cristã pelo entendimento racional, usando a lógica e o silogismo e iii. enriqueceu qualitativamente a produção intelectual da Idade Média, nos possibilitando conhecer o trabalho acurado de seu pensamento instigante, que alimenta o trabalho de reflexão e engrandece a humanidade como um todo.

A fé na Idade Média não é, portanto, objeto cego, imposto de forma irracional, como se faz acreditar alguns teóricos da nossa modernidade. Hoje, vivemos um momento em que á fé é banalizada, ridicularizada nas igrejas de diferentes segmentos. Pressupõe mentes débeis o suficiente para acreditar sem argumentar, ler sem entender, ouvir sem refletir. Utiliza-se de discursos infundados que contrariam não apenas a racionalidade como também os princípios da própria doutrina cristã.

A leitura do trabalho desses mestres medievais nos provoca importantes reflexões a respeito não apenas das questões da fé, mas sobre tudo aquilo que diz respeito à existência humana nos planos individual e coletivo.

Mais do que importante, o trabalho desses dois grandes intelectuais é uma necessidade e um exemplo, em um momento em que está se perdendo o critério do rigor na pesquisa, a disciplina, o estudo, o respeito aos argumentos e a discussão teórica de alto nível na academia. 
Diante disto, a Idade Média vista sob o olhar da modernidade não pode ser injustamente acusada de obscurantismo pelo fato de que, esse momento da nossa historia é responsável pela conservação do pensamento clássico greco-romano ate hoje e por representar um período de efervescência filosófica autêntica e indispensável à construção do pensamento teórico da modernidade, como observa Zilles (1996, p. 56):

A Idade Media é, pois, muito mais que um período histórico colocado entre algo que o antecede e algo que vem depois. [...] O que a distingue é um sentido próprio e singular da vida. Por um lado é uma época limitada, com características e realizações próprias; por outro, é preparação e antecipação, sob muitos aspectos, da Idade Moderna.

Fica, portanto, o imperativo de conhecer profundamente a produção intelectual desse período da história da humanidade, com sua riqueza e profundidade de pensamento, como fundamento para a compreensão de toda a reflexão elaborada na posterioridade.

\section{Referências bibliográficas:}

BÍBLIA SAGRADA. Trad. João Ferreira de Almeida. 9. ed. - São Paulo - Edições Paulinas, 2007.

BOEHNER, Philotheus; GILSON, Etienne. História da filosofia cristã. 5. ed., 1991.

FRANCO JÚNIOR. A Idade Média: nascimento do ocidente. Nova ed., rev. e ampli. - São Paulo - Brasiliense, 2004.

HENRI MARROU. Santo Agostinho e o agostinismo. Trad. Ruy Flores Lopes. - Rio de Janeiro - Agir Editora, 1957.

SAN AGUSTIN. Obras. Tomo VII. Sermones. Trad. Fr Amador Del Fueyo, O. S. A. 2. ed. Madri - Biblioteca de Autores Cristianos, S/D.

TOMÁS DE AQUINO. Suma Teológica. Trad. Carlos-Josaphat Pinto de Oliveira (coord. Geral) 2. ed. - São Paulo - Edições Loyola, 2003.

TORRELL, Jean-Pierre. Iniciação a Santo Tomás de Aquino: sua pessoa e obra. - São Paulo Loyola, 1994.

ZILLES, Urbano. Fé e razão no pensamento medieval. 2. ed. - Porto Alegre - EDIPUCRS, 1996. 